\title{
Investimentos no Cárcere: o Menor dos Males na Política de Segurança Pública
}

\author{
Oriana Hadler ${ }^{1}$ \\ Neuza Maria de Fátima Guareschi ${ }^{1}$ \\ ${ }^{1}$ Universidade Federal do Rio Grande do Sul, RS, Brasil. $\quad{ }^{1}$ Universidade Federal do Rio Grande do Sul, RS, Brasil.
}

Resumo: Este artigo objetiva discutir as práticas Estatais produzidas no campo da Segurança Pública, principalmente relacionadas às políticas penais. Fundamentamo-nos nos estudos de Michel Foucault para realizar a análise de documentos relacionados a recursos e ações voltadas ao sistema carcerário do estado do Rio Grande do Sul e notícias veiculadas pela mídia impressa e digital. A análise parte de três vetores vinculados ao investimento em Segurança Pública, quais sejam: o investimento na segurança pública a partir da formação profissional e otimização das condições de trabalho articuladas a este campo; o investimento relacionado a ampliação de vagas e/ou criação de novos estabelecimento no sistema prisional; por fim, o investimento a partir da problematização das penas alternativas que se constituiriam como opção para romper com a racionalidade carcerária. Concluímos que os investimentos realizados não têm produzido redução no cometimento de crimes ou a melhora nas condições carcerárias, mas, sim, a ampliação das formas de encarceramento que incidem sobre corpos constituídos enquanto criminosos. Operacionalizam-se, assim, medidas que se pautam em um arranjo arbitrário de legalidades, permitindo que uma gama de ações seja realizadas em nome da segurança a partir de um cálculo mínimo sobre vidas a serem gerenciadas em um plano de investimento entre baixos custos e a menor repercussão possível, combinada com a ampliação e execução de práticas violentas.

Palavras-chave: Psicologia; Segurança Pública; Encarceramento; Violência do Direito.

\section{Investments in the Jail: The Lesser of Two Evils in Public Security Policy}

\begin{abstract}
This article aims to discuss the State practices produced in the field of Public Security, mainly related to criminal policies. We based our studies in Michel Foucault with the purpose of carrying out the analysis of documents related to the resources and actions directed to the prison system of the State of Rio Grande do Sul and on news published by print and digital media. The analysis starts from three vectors linked to the investment in Public Security, namely: the investment in public security through the professional training and improvement of working conditions articulated to this field; the investment related to the increase of vacancies and / or creation of new facilities in the prison system; finally, the investment through the problematization of alternative sentences that would constitute as an option to break with this prison rationality. We conclude that the investments made have not produced a reduction in the number of crimes committed or an improvement in prison conditions, but rather an increase of the forms of incarceration that affects the subjects constituted as criminals. Then, the measures that are created are based on an arbitrary arrangement of legalities, allowing a range of actions to be carried out in the name of public security that are based on a minimum calculation about the lives to be managed in a low-cost investment plan and with low effects, combined with the increase of the prison system and the execution of violent practices.
\end{abstract}

Keywords: Psychology; Public Security; Incarceration; Legal Violence. 


\title{
Inversiones en la Cárcel: El Menor de los Males en la Política de Seguridad Pública
}

\begin{abstract}
Resumen: Este artículo objetiva discutir las prácticas Estatales producidas en el campo de la Seguridad Pública principalmente relacionadas a las políticas penales. Nos fundamentamos en los estudios de Michel Foucault para realizar el análisis de documentos relacionados a los recursos y acciones dirigidas al sistema carcelario del Estado de Rio Grande do Sul y noticias transmitidas por los medios impresos y digitales. El análisis parte de tres vectores vinculados a la inversión en Seguridad Pública, estos son: la inversión en seguridad pública a partir de la formación profesional y optimización de las condiciones de trabajo articuladas a este campo; la inversión relacionada al aumento de plazas y/o a la creación de nuevos establecimientos en el sistema penitenciario; por fin, la inversión a partir de la problematización de las penas alternativas que se constituyeron como opción para romper con la racionalidad carcelaria. Concluimos que las inversiones realizadas no han producido reducción en la comisión de crímenes o en la mejora de las condiciones carcelarias, sino en el aumento de las formas de encarcelamiento que inciden sobre los cuerpos constituidos como criminales. Se operan así, medidas que se pautan en un arreglo arbitrario de legalidades, permitiendo que una gama de acciones sean realizadas en nombre de la seguridad a partir de un cálculo mínimo sobre vidas a ser gestionadas en un plan de inversión entre bajos costos y la menor repercusión posible, combinada con la ampliación y ejecución de prácticas violentas.
\end{abstract}

Palabras clave: Psicología; Seguridad Pública; Encarcelamiento; Violencia del Derecho.

\section{Introdução: o Central e a Capitalização da Segurança Pública}

O Central, como usualmente conhecido, passou por duas mudanças em sua nomenclatura no decorrer de sua história. A primeira aconteceu na gestão da governadora Yeda Crusius (2007-2010) quando esta, após o falecimento de um dos antigos diretores do estabelecimento prisional, homenageia-o aderindo seu nome ao da instituição que se torna Presídio Central de Porto Alegre - Ten. Cel. Jainer Pereira Alves. Nomear o presídio com esta alcunha deve-se não somente pelo reconhecimento ao tenente-coronel enquanto diretor do presídio, mas também por suas táticas de controle e conduta criadas junto à Brigada Militar. Na década de 1990, o tenente-coronel Jainer Pereira Alves cria o Grupo de Apoio e Movimentação (GAM), equipe de elite para trabalhar na prevenção de fugas e domínio de tumultos no interior dos estabelecimentos prisionais então administrados pela Brigada: o Presídio Central e a Penitenciária Estadual do Jacuí (PEJ). Na época, a força-tarefa da Brigada Militar havia sido acionada para controlar rebeliões envolvendo o Central e a PEJ, as quais, somando-se a políticas estaduais repressivas, culminaram na entrega da administração destes dois estabelecimentos prisionais à Brigada Militar como medida de segurança pública para um cenário de crise. É assim que a Brigada Militar passa a ter o controle e direção do Central, iniciando como uma medida emergencial que mantém-se até hoje.

A segunda nomeação do Central acontece no final de 2016, quando este passa a denominar-se Cadeia Pública de Porto Alegre após o Decreto ${ }^{\circ}$ 53.297, de 10 de novembro de 2016. Determinada pelo governador José Ivo Sartori (2015-2018), esta última modificação tem como propósito forçar a regularização deste estabelecimento, tendo em vista o objetivo para o qual é destinado desde sua construção: ser uma casa de detenção para regimes de provisoriedade. Criado para manter sob custódia presos provisórios, cujos julgamentos ainda não aconteceram e que, porquanto, aguardam o andamento de seu processo recolhidos em prisões, o Central figura-se como presídio ao manter presos condenados e provisórios em um regime misto. São cerca de 2030 condenados cumprindo pena em cárcere fechado e, considerando que a decisão proibitiva de manter presos condenados neste estabelecimento exista há mais de duas 
décadas, a princípio tal diferenciação nominal não representa modificações efetivas. "O sistema penitenciário é o lugar em que mais coisas que não poderiam acontecer, acontecem. [...] Não é porque trocam a placa na frente que vai mudar a realidade lá dentro. Ela só muda com ações concretas", diz Gilmar Bortolotto, procurador do Estado que vem acompanhando a realidade do Central na última década (Canofre, 2017, fevereiro 11).

Tendo em vista as condicionalidades que tornam o Central possível de existência e, ao mesmo tempo, uma iconografia do cenário prisional brasileiro, este artigo objetiva discutir as práticas estatais produzidas no campo da Segurança Pública, principalmente no que diz respeito às políticas penais. Considerando que partimos de uma analítica foucaultiana, ao realizar um levantamento de documentos relacionados a recursos e ações voltadas ao sistema carcerário do estado do Rio Grande do Sul e notícias veiculadas pela mídia impressa e digital, as discussões aqui apresentadas passam a direcionar-se, em um primeiro momento, para a problematização de três vetores vinculados ao investimento em Segurança Pública. O primeiro vetor aborda o investimento na segurança pública, a partir da formação profissional e otimização das condições de trabalho. O segundo vetor tem como foco o investimento no que diz respeito a ampliação de vagas e/ ou criação de novos estabelecimentos no sistema prisional. $\mathrm{O}$ terceiro vetor toma o investimento a partir da problematização das penas alternativas que se constituiriam como opção para romper com a racionalidade carcerária.

Diante das análises realizadas acerca desses três vetores, em um primeiro momento da escrita argumentamos que violência e crime abrem espaço no campo da Segurança Pública enquanto elementos de consumo a serem capitalizados, articulando-se enquanto força que agenciam diversas estratégias de barbárie e controle sobre corpos, através do atrelamento entre público e privado. A seguir, apontamos como efeitos dos investimentos realizados acerca da temática da segurança não uma redução no cometimento de crimes ou sequer a melhora nas condições carcerárias, mas, ao contrário, a ampliação das formas de encarceramento que incidem sobre corpos constituídos enquanto criminosos. Neste cenário, o encarceramento se apresenta pela contenção de corpos em ônibus-cela, contêineres, aprisionamento dentro de viaturas e até mesmo algemamento em lixeiras daquelas pessoas que aguardam abertura de vagas no sistema prisional. Por fim, apresentamos e discutimos o modo como a lógica do "menor dos males" e da figura do "militar" opera enquanto forças que fazem a manutenção das racionalidades do poder que incidem diretamente na vida daqueles sujeitos identificados enquanto criminosos no interior das políticas de segurança. Tal manutenção se relaciona menos à ideia de execução de medidas fundamentadas em leis, do que a uma suspensão de um ordenamento jurídico-legal, fazendo funcionar todo um arranjo arbitrário de legalidades que permite que quaisquer (bárbaras) ações sejam realizadas em nome da segurança. Trata-se de um cálculo mínimo sobre vidas a serem gerenciadas em um plano de investimento entre baixos custos e a menor repercussão possível combinada com a ampliação e execução de práticas violentas que extrapolam o âmbito do direito.

\section{Investimentos no cárcere, cálculos sobre a Vida}

A fim de iniciar as problematizações sobre os investimentos no cárcere e os cálculos sobre a vida tomamos a série "Retratos do Cárcere", exibida em canais por assinatura e lançada em 2017 contendo 13 episódios de 26 minutos sobre o sistema penitenciário brasileiro, como analisador para o enfoque midiático sobre as prisões consideradas mais problemáticas no país, dentre as quais está o Presídio Central de Porto Alegre (PCPA). A ideia para a série surgiu a partir do documentário intitulado "Central" (Sager, \& Rodrigues, 2015) inspirado no livro de Renato Dornelles "Falange Gaúcha”. A produção documental narra a história do crime organizado e a criação de facções no Rio Grande do Sul desde os anos 1970, bem como as situações de violências e rupturas de direitos pelas quais os presos passam nessa instituição. Utilizado como ferramenta para o que os diretores chamam de "missão social de Central", o filme vem sendo exibido em fundações de atendimento socioeducativo (FASE) sob o teor de conscientizar os jovens sobre os terrores do presídio. Já a série toma este último enfoque para dar visibilidade à degradação humana e os motivos que colocam o PCPA como um dos piores presídios da América Latina e que levou o Brasil à Corte Interamericana de Direitos Humanos. Ambos apostam no dispositivo visual como choque para denunciar a superlotação e as condições atrozes do Central: "O documentário mostra que, quanto mais 
superlotado o presídio, menor é a interferência do Estado e mais se fortalecem as facções comandando crimes, como o roubo de carros, de dentro da cadeia" (Requião, 2016).

A lógica do abandono do Estado frente à problemática do hiperencarceramento e da importância não só de vagas, como de parcerias público-privadas que invistam em projetos humanitários, educacionais e de reabilitação junto a presos dá o tom para o documentário, que lança uma crítica sobre a falência do sistema prisional brasileiro e uma leitura das prisões como escolas do crime. "É preciso prender melhor e não mais" (Brzuska, 2016). Nesses termos, os pesquisadores e profissionais entrevistados que aparecem no filme fazem um levantamento da urgente necessidade de se pensar outras práticas e racionalidades sobre o crime e formas de punição. Um discurso de mudança que atinge três vetores no qual a palavra "investimento" passa a ditar as regras para políticas penais: investir na segurança pública no âmbito da formação profissional e otimização das condições de trabalho; investir no sistema prisional através da ampliação de vagas e/ou criação de novos estabelecimentos; e investir em penas alternativas que possam realmente romper com a racionalidade carcerária.

Em relação ao investimento em segurança pública, as ações que se voltam à formação e qualificação na área passaram a chamar a atenção principalmente de instituições privadas de ensino superior. É assim que vemos nos últimos anos uma proliferação de cursos de formação, bacharelado, especialização, entre outros, na área da segurança. Só em Porto Alegre e região metropolitana encontramos a criação de diversos cursos superiores em Segurança Pública (PUC-RS, Fapergs), Tecnólogos e Gestão em Segurança Pública (Universidade Feevale, FTEC/IBGEN), além de cursos a distância (Uninter) e cursos de pós-graduação Segurança Pública e Privada (Ulbra).

Além destes espaços, outras universidades como a Universidade Federal do Rio Grande do Sul (UFRGS) apostam em uma parceria com o governo federal através da Rede Nacional de Altos Estudos em Segurança Pública (Renaesp). Criada em 2003 pelo Ministério da Justiça, a Renaesp surge com o objetivo de pensar uma segurança cidadã, pautada em uma perspectiva coletiva de democratização de saberes, onde academia, sociedade e órgãos de segurança pública teriam como enfoque o trabalho interdisciplinar para a capacitação profissional não somente de seus servidores, como também de outros atores da sociedade a fim de trazer novas perspectivas no enfrentamento à cultura de violência perpetuada no cenário brasileiro (Costa, 2011; Lima, Bueno, \& Mingardi, 2016).

Ao nos enveredarmos nas propostas e propagandas dos cursos, encontramos como diferencial de empregabilidade os quesitos "aumento da violência" e "complexidade do sistema prisional", para os quais seus formandos se tornam profissionais necessários dadas as condicionalidades gaúchas frente à criminalidade crescente. Nesse cenário a violência torna-se campo de consumo e o crime, recurso econômico a ser capitalizado. A prisão vai cedendo seu lugar de escola do crime, que passa para as faculdades que fazem uso do crime como combustível curricular lucrativo. Ainda que falando de um contexto europeu ocidental, Earle (2011) também observa a expansão de cursos que visam especializar sujeitos a lidarem com a tríade crime, violência e segurança. Em sua análise, o autor desenrola a relação entre universidade e prisão como desproporcional, nas quais ao sujeito da primeira é oferecido o prestígio neoliberal máximo - tornar-se empresário de si-, enquanto o sujeito da prisão é premiado com a garantia de jazer no fundo da estrutura social - torna-se apenas o melhor que conseguir ser. Há, nessa relação, um "cortejo triunfal”, como Benjamin (1987, p. 225) diria, onde legitima-se barbárie na presunção de saberes industrializados.

Ressaltamos, contudo, que a relação entre academia e prisão não pode ser reduzida a uma lei de mercado, a um desejo de produzir capital e girar a economia. Precisamos deixar claro que pensamos tais instituições, e suas relações, como processos constituídos por múltiplos agenciamentos. Afinal, como diz Massumi (2016, pp. 23-24), o "campo capitalista é repleto de tendências que corporificam relações, as quais não podem ser reduzidas à relação capitalista em si; e não é apenas repleto delas: elas estão constantemente se automultiplicando e se diferenciando". Isto significa dizer que a questão não é o porquê da existência dessa relação, tampouco ela ocorrer de forma paradoxal - uma vez que o paradoxo diz de um "manancial de tenacidade e astúcia, de humor, de resistência e de questionamento" das continuidades (Gagnebin, 2008, p. 80) -, mas problematizarmos como essa relação passa a existir, como ela é produzida, que atores ela convoca, quais forças ela condena, que incumbências recebe, quais ordenamentos responde, a que regimes de veridicção remete? 
Assim, se por um lado temos planos governamentais que lançam projetos de formação marcados pelos discursos de "comprometido com a cidadania e os direitos humanos" (Brasil, 2003), e por outro, há a capitalização desses discursos enquanto ferramentas de governo neoliberais, para além disso existem outras racionalidades e fluxos de vida que não são necessariamente aprisionados (para fazer um jogo de palavras dentro do espectro da segurança) pela lógica capital, mas constituem-se modos de vida que transbordam essa questão. A postura diante da proliferação de cursos sobre Segurança Pública é a do estranhamento. E nesse processo de estranhar os acontecimentos, observamos que há um certo sopro de crítica que também passa a habitar esses espaços:

Nosso desassossego é incontrolável. Então sabemos porque junto à porta da sala de espelhos do logos hegemônico sempre encontra-se um estudante. Cada um espera ali a sua vez para encontrar justamente aquilo que deseja desconstruir. Eles esperam uma chance; batem na porta e estudam. - Ouvimos o mal-estar contemporâneo? Não é um canto. São gritos. Pauladas. Levam ao abandono. Mas quebra-se o encanto da sala de espelhos? Não esperamos agora uma descrição factual do contínuo ininterrupto maquinário racional de harmonização e apaziguamento da consciência da debilidade social. A quem perguntar para onde leva tal colocação, respondo que leva a violência à crise e o estudioso às camadas subjacentes à injustiça histórica. Ali encontramos os corpos que são os ossos da nossa sociedade. A crítica da violência e do crime abala a ortodoxia articulada ao todo do estado (Pandolfo, 2014, pp. 213-4).

Porém, é ainda Pandolfo (2014) que nos alerta para as agências de controle, das teorias oportunistas e dos "esquemas de calculabilidade que invariavelmente" importam ao Estado investir quando se trata de sistema prisional. É assim que robustas teorias propagam a necessidade de parcerias público-privadas
(PPP) que culminam no fortalecimento das propostas de privatização do sistema penitenciário brasileiro. “Ora, um presídio privado está embebido na relação capitalista. Ele participa dela por todos os lados, inclusive o de dentro. Ele vive em função dos fluxos de capital que captura e canaliza para a produção de mais-valia" (Massumi, 2016, p. 22). É nesse ponto que pensamos sobre o próximo vetor que mobiliza investimentos para o campo da segurança pública: o investimento no sistema prisional através da ampliação de vagas e/ou criação de novos estabelecimentos.

Ao fazer um levantamento junto aos arquivos públicos da Assembleia Legislativa do Rio Grande do Sul, e pesquisar documentos relacionados a recursos ou ações voltadas para o sistema carcerário do Estado, encontramos, nos últimos dez anos, 45 decretos de abertura de créditos suplementares que continham encaminhamentos de fundos para estabelecimentos prisionais ${ }^{1}$. Dentre as justificativas apresentadas nestes documentos, alguns alocando gastos com alimentação e vigilância, outros apontando a necessidade de reformas dos locais e/ou investimento em cursos profissionalizantes, uma frase surge em todos os decretos: “ampliação de vagas prisionais". Proliferam-se cursos em Segurança Pública quando a academia encontra a prisão, quando do encontro desta última com a agenda estatal, o que encontramos é a necessidade de mais vagas. Ao que tudo indica, as pautas estatais que negociam o imperativo da segurança pública 'é preciso proteger a sociedade' (Foucault, 2005), traduz-se na agenda governamental por "é preciso prender mais". Dentre as verbas arroladas, o investimento tido como essencial para o sistema prisional resume-se à criação de mais espaços de aprisionamento, mais buracos no cárcere, mais camas gradeadas.

Somente nos primeiros dois anos da atual gestão do governador José Ivo Sartori (2015-2018), foram oito decretos; o último, publicado em 25 de agosto de 2016 (mesma data em que efetiva-se o pedido de exoneração do então Secretário de Segurança Pública Wantuir Jacini), solicita o montante de $\mathrm{R} \$ 44.652 .800,65 \mathrm{em}$ créditos suplementares, dentre os quais são encaminhados $\mathrm{R} \$ 86.337,87$ para a ampliação de vagas nos presídios (Decreto No 53.297, 2016a). Exatamente

${ }^{1}$ Pesquisa realizada em janeiro de 2017 através do banco de dados online da Assembleia Legislativa do Rio Grande do Sul, na qual foram elencados todos os decretos publicados em Diário Oficial do Estado que continham alguma ação voltada ao sistema prisional. Nesta busca, encontramos documentos datados entre 1966 e 2016, os quais apresentavam temáticas variadas - desde a aprovação de regimentos disciplinares, a criação ou desativação de instituições penais, até a disposição de nova organização da Secretaria de Justiça. Contudo, os primeiros decretos de abertura de créditos suplementares contendo encaminhamentos de fundos para estabelecimentos prisionais só aparecem a partir de 2009, com o Decreto n 46.225, de 17 de fevereiro de 2009. 
uma semana após esse documento, um novo é publicado decretando situação de emergência no sistema prisional do Estado, tendo como indicativo máximo e primeiro ponto destacado como causa para a conjuntura emergencial a carência de vagas prisionais (Decreto No 53.176, 2016b). Seguindo este ponto, o decreto considera a população carcerária de mais de 34 mil pessoas, as deficientes estruturas prisionais (contando com interdições judiciais de alguns estabelecimentos ${ }^{2}$ ) e o aumento da criminalidade, como os dados que sustentam "a mais grave crise da história do Rio Grande do Sul” - assim estampado na capa da revista Veja impressa no mês seguinte à publicação do decreto (Nunes, 2016, setembro 28). Note-se, contudo, que a pior crise da história apontada pela revista baseia-se em um gráfico comparativo de homicídios dolosos cuja linha temporal não abrange mais do que dez anos, localizando-se entre 2006 e 2016.

Nessa analítica dos últimos dez anos, foi sob o mote da crise que o governo estadual passa a desenvolver programas de policiamento ostensivo e aumento de prisões preventivas (sem condenação). Tendo em mente que violência se controla com intensificação policialesca e mais aprisionamentos, durante o ano de 2016 uma das medidas adotadas no campo da Segurança Pública no Estado foi o desenvolvimento da chamada "Operação Avante". Projetada conjuntamente pela Secretaria de Segurança Pública (iniciando com o secretário Wantuir Jacini e tendo continuidade com seu sucessor, Cezar Schirmer) e a Brigada Militar, a operação vem sendo coordenada pelo Comando de Policiamento da Capital (CPC) e operacionalizada pelos policiais militares. Tal operação consiste em três fases de atuação: a instalação de barreiras de monitoramento em locais estratégicos da capital gaúcha elencados após levantamentos dos bairros com maior taxa de latrocínios; a repressão da criminalidade em pontos estratégicos, especialmente em Porto Alegre e Novo Hamburgo (territórios que representam $80 \%$ das ocorrências de roubos e assaltos conforme análises criminais feitas por estas instâncias); e, na terceira fase, a incorporação de agentes da Força Nacional enviados pelo governo federal após o decreto de emergência. Somando-se a isto, uma mobilização de tecnologias e aparatos especializados para abordagens noturnas, bem como helicópteros e carros reforçados foram vistos ocupando ruas e céus da cidade.
Em um mês de atuação, a "Operação Avante" diminuiu em $41 \%$ os roubos e aumentou em $63 \%$ as prisões flagrantes. Em um ano, a operação apresentou como resultados "positivos" o aprisionamento de mais de 4 mil pessoas (Decreto No 53.176, 2016b). As contradições nesse quadro estão para além da obviedade e chegam ao surrealismo, não só pela sobrecarga de um sistema já inconcebivelmente superlotado de gente, como na adoção de uma estratégia de segurança que recorre à punição como alternativa para o crime. Aparentemente a solução para a redução da superlotação só consegue ser prender mais. É assim que as propostas criadas para desafogar as instituições carcerárias acabam saindo como um tiro pela culatra, pois são pensadas em um contexto político-criminal onde justiça amarra-se com punição. Essa lógica produz efeitos também nos modos como as alternativas penais são pensadas, justificadas e implementadas, servindo para reforçar o lugar que o cárcere ocupa nas práticas estatais penais.

Nesse âmbito, se pensarmos no terceiro vetor mencionado anteriormente, o investimento em penas alternativas, a aplicação destas não representa de forma nenhuma uma ruptura com a racionalidade carcerária: não há alternativas à prisão, mas a ampliação de condições que retornam a ela. "[A prisão] é um dos instrumentos do poder, e um dos mais desmedidos" (Foucault, 2006, p. 26). Em sua análise voltada para a problematização dos discursos sobre crime e punição na produção de alternativas à prisão no Brasil, Souza (2014) coloca que, mesmo buscando um deslocamento do cárcere como principal resposta para o crime, tais medidas não serviram para romper com a lógica punitivista, quanto mais para a redução do encarceramento; pelo contrário, o número de Penas Restritivas de Direito (Lei No 7.209/1984; Lei $\left.\mathrm{N}^{\circ} 9.714 / 1998\right)$ cresce tanto quanto o aglomerado humano enviado às instituições prisionais. Junto a isso, a banalização das prisões cautelares e a asfixia morosa do judiciário (com audiências de custódia, por exemplo, pensadas para atenderem os sujeitos imediatamente após a detenção, acontecendo dias após os detidos já somarem-se ao número de presos) aliam-se com um populismo punitivo no qual a ideia de que um sujeito possa responder processos em liberdade traduz-se por impunidade. Há desejo de sangue. Dos outros.

${ }^{2}$ Em 2015, foram cinco interdições do Presídio Central de Porto Alegre, quadro este que se repete em 2016 causando a superlotação das delegacias da capital e região (Martins, Abati \& Rosa, 2015; Jacobsen, 2016; Kannenberg, 2016; Torres, 2016). 
Não só Souza (2014) como Lima (2004), ao tratarem sobre a cultura jurídica brasileira, sustentam que o modo de pensar o cárcere torna-se a racionalidade que legitima às penas alternativas reforçarem a cisão entre "sujeitos perigosos" e aqueles "sem periculosidade", perpetuando o tratamento desigual do sistema de justiça criminal. Tal proposição fica explícita nas ações voltadas às políticas de criminalização das drogas. Comemorada como um avanço humanitário no cenário do tratamento penal, a Lei No 11.343/2006 tratava de discorrer sobre o tráfico de drogas, reconhecendo a figura do usuário e lhe propondo um tratamento descriminalizado, aparentemente diferenciado daquele voltado para o "verdadeiro delinquente" - o traficante. Contudo, uma década após a implementação dessa lei, o que se registra como efeito direto dela é o aumento da população carcerária em função do tráfico. Nela, tráfico e porte de drogas conjugam-se sob as mesmas condutas objetivas (adquirir, guardar, ter em depósito, transportar ou trazer consigo), sendo determinantes na distinção entre traficante e usuário somente os critérios de interpretação dos juízes e, antes disso, do policial que realizou a abordagem do sujeito (Carvalho, 2006; 2013). O Presídio Central de Porto Alegre sente nas entranhas o efeito desse processo: de seus 4.576 presos provisórios e condenados, 2.368 deles estão trancafiados por tráfico de drogas, ou seja, mais da metade de sua população ${ }^{3}$.

A política de guerra às drogas passa a ser mais uma das justificativas que encadeiam o aumento de aprisionamentos e, inclusive, fortalecem a discussão para que mais vagas sejam criadas no sistema prisional. Um terrorismo de Estado que volta sua atenção para a figura do traficante como inimigo interno. Esse defensivismo dá as dimensões para os três vetores de investimentos mencionados anteriormente referentes à racionalidade punitiva e manutenção do cárcere. É sob o mote de que segurança se faz com prisão que a retórica das mais vagas segue os governos estaduais para colocarem mais policiamento, mais penas (e nesse ponto não interessa que sejam chamadas de alternativas, pois elas somam-se e não substituem a punição), mais prisões, mais dinheiro para tecnologias ostensivas e mais políticas de prevenção, voltadas para intervenções em comunidades pobres que, por sua vez, culminam na criminalização de certos grupos populacionais. Nesse arranjo fortalecem-se as parcerias público-privadas, que emergem justificando a criação de novos estabelecimentos pela lógica do "começar do zero": "Em um sistema novo, tem que levar o preso novo, 'descontaminado', e não deixar entrar a cultura velha, das facções. É preciso preservar os novos espaços e alimentá-los com uma nova cultura", conclui o procurador Gilmar Bortolotto (Dornelles, 2017). Mais investimentos. Essa é a lógica que marca a fala de pesquisadores, juízes, profissionais do campo da segurança. Entre levas de aberturas de créditos e novos estabelecimentos prisionais, um jogo governamental de fazer o máximo pelo mínimo é posto em cena.

Desde o governo de Antônio Britto (1995-1998), passando pelas gestões posteriores de Olívio Dutra (1999-2002), Germano Rigotto (2003-2006), Yeda Crusius (2007-2010), Tarso Genro (2011-2014) e o atual mandato de José Ivo Sartori, a construção de mais vagas no sistema prisional gaúcho está em voga, bem como a desativação do PCPA buscando soluções que custem menos ao Estado. Iniciando seu mandato após a rebelião mais conhecida do Central, com fuga de detentos e tomada de reféns por líderes de falanges gaúchas, marcando a entrada da Brigada Militar na coordenação do estabelecimento, Britto lançou o projeto de demolir o presídio. Esse plano vigora até hoje, sendo marcado por pronunciamentos oficiais e angariamento de fundos para a construção de outras prisões (as quais, em tese, aliviariam a população do Central); sem ser levado a cabo, seus decrépitos muros continuam em pé. "Elaboramos projetos para a criação de 8.914 novas vagas nos presídios estaduais, com investimentos de R\$ 170 milhões", dizia Rigotto em 2006. "A decisão de implosão do Presídio Central está tomada", lançava Crusius, dois anos depois. "O nosso objetivo estratégico é chegar ao final de 2014 com o presídio desocupado. Se isto não for possível, em função de atrasos de obras, teremos reduzido em um terço a população do Central", oficializava Tarso ${ }^{4}$. Em um jogo de demole-não-demole, aproveitamentos de antigos pavilhões, construção de novos, reformas de outros, e até mesmo a destruição do Pavilhão C (no final do mandato de Tarso), uma

\footnotetext{
${ }^{3}$ Levantamento de fevereiro, 2017 (Gomes, 2017).

${ }^{4} \mathrm{~A}$ linha do tempo de promessas e oficializações de governadores do Estado foram levantadas a partir dos decretos analisados; já as entrevistas e citações sobre o Presídio Central apresentadas aqui foram retiradas de diversos sites de reportagem, a ver cronologicamente: Sturn (2013), Moreira (2015), Ruas (2016).
} 
complexa gama de negociações passa a se engendrar, levando as ações no âmbito da segurança a tornarem-se da ordem do ubuesco.

\section{A racionalidade do "menor dos males" na Segurança Pública}

Se no núcleo do exame médico legal, Foucault (2013) encontra aquilo que ele nomeia como ubuesco $^{5}$, o caráter grotesco do poder médico-judiciário a reinventar categorias elementares da moralidade que se organizam em torno da perversidade e do perigo, é na bufonaria dos cálculos de investimentos e seus arrochos contemporâneos que a margem para o bizarro se alarga. Entre os cientistas da verdade sobre a segurança e as decisões decretadas sobre o que fazer com o sistema carcerário, um espetáculo grotesco se desenrola. Nos discursos de vida e de morte na segurança, na palavraria dos profissionais especialistas, nas decisões que libertam ou trancafiam e, inclusive, no desespero cômico do trágico cotidiano, está o ubuesco.

Mostrando explicitamente o poder como abjeto, infame, ubuesco ou simplesmente ridículo, não se trata, creio, de limitar seus efeitos e descoroar magicamente aquele a quem é dada a coroa. Parece-me que se trata, ao contrário, de manifestar da forma mais patente a incontornabilidade, a inevitabilidade do poder, que pode precisamente funcionar com todo o seu rigor e na ponta extrema da sua racionalidade violenta, mesmo quando está nas mãos de alguém efetivamente desqualificado (Foucault, 2013, p. 13).

Das negociações que chegam em soluções bizarras, destacamos as criações como o ônibus-cela e os contêineres para manter os detidos esperando a abertura de uma vaga no sistema prisional. Depois de manter presos autuados em flagrante dentro de viaturas ou ainda algemados a lixeiras na frente do Palácio da Polícia, em Porto Alegre, a Superintendência de Serviços Penitenciários (Susepe) cria o ônibus-cela como possibilidade temporária para manter os detidos com um mínimo de estrutura. Pintado de preto e reformado para ter condições mínimas de higiene, esse recurso foi considerado excelente para
Cézar Schirmer (Secretário de Segurança), principalmente por ser ágil e sem custos. "Conhecido no passado como Trovão Azul, o veículo foi utilizado pela Susepe por cerca de 30 anos no transporte de presidiários, tendo sido aposentado em 2013 e agora reativado para a nova missão" (Correio do Povo, 2016). Em uma reportagem que acompanhou os primeiros usos do micro-ônibus, este é referenciado como solução inteligente para a superlotação, pois evita que uma viatura fique fora de circulação, para continuar prendendo mais. O repórter anuncia: "Então essa é a novidade, não é ainda um navio, não é um contêiner, mas é um micro-ônibus". Ao que tudo indica, há possibilidades inclusive de se retornar à "Nau dos Loucos", que levava aqueles considerados degenerados e os largava em alto-mar. Quanto aos contêineres, estes parecem ser uma proposta de realização ainda para o mandato de Sartori, com o anúncio de Cézar Schirmer de que o governo do Estado está em negociações para adquiri-los. Continua o repórter: "Serão 16 celas que podem comportar, ao todo, 96 presos. Cada contêiner terá três beliches com cama e ainda um banheiro com chuveiro. Schirmer reforçou ainda que os presos vão ficar no máximo $48 \mathrm{~h}$ nos espaços, que serão provisórios" (Ledur, 2016).

A narrativa de García Márquez (2014, p. 341) ressoa a nós quando a palavra contêiner é exposta como possibilidade para trancafiar os presos "provisoriamente": "Percebeu que ia num trem interminável e silencioso, e que estava com os cabelos engomados de sangue seco, e que todos os seus ossos doíam. [...] Não havia espaço livre no vagão, a não ser no corredor central". Sabendo que o cárcere transforma antíteses gramaticais em realidades cruas - o provisório que se torna permanente, o confinamento que expõe (à violência, à fome, à deterioração), o aprisionamento que "liberta" (o sujeito do criminoso) - questionamo-nos o que podemos esperar dos vagões de metal para guardar humanos? A resposta a essa questão, sob uma lente econômico-jurídica, é a do "menor dos males". O menor dos males passa a ser a racionalidade que determina cálculos mínimos sobre vidas a serem gerenciadas em um plano de investimento entre baixos custos e a menor repercussão possível. Em um contexto no qual medidas estatais para contingenciamentos de gastos na segurança resultam em um jogo de parcelamento de salários dos servidores públicos, cortes em

${ }^{5}$ Em Os anormais, Foucault (2013) discorre sobre o ubuesco a partir da peça “Ubu Rei” (1896), que diz de um personagem absurdo, cruel e caricato, de "caráter comicamente cruel, cínico e covarde ao extremo" (p. 25). 
diversas áreas (combustível de viaturas, horas extras, diárias, compras de equipamentos) e a promessa de novas contratações de policiais quando um número maior de aposentadorias é efetivado ${ }^{6}$, uma série de cálculos passam a determinar que vidas importam, como importam, até onde e quando importam.

Nesse pontoWeizman (2011), arquiteto israelense e pesquisador de Culturas Visuais pela Goldsmiths College em Londres, traz importantes considerações sobre o princípio de cálculos mínimos sobre a vida, as quais trazemos aqui para pensarmos essa mecânica de investimentos sobre o cárcere. Em uma análise onde inverte o esquema leibniziano de 'o melhor dos mundos possíveis'(Leibniz, 2017), o autor parte de uma série de investigações sobre locais contemporâneos em situação de conflitos armados, problematizando debates legais sobre espaços geográfico-arquitetônicos (a construção do muro de separação entre Israel e Palestina como um deles) questionando como a racionalidade do 'menor dos males' é invocada para justificar violências de Estado. Em seus estudos, Weizman propõe o quanto há uma elasticidade de negociações que surgem quando se trata de investimentos que envolvem a liberdade e a morte de pessoas. É a emergência de uma mecânica burocrática e um campo de negociações onde o menor dos males possíveis serve como parâmetro para decisões, uma lógica que

emerge como um compromisso pragmático, um "pecado tolerável" que funciona como justificativa para a noção de exceção. [...] $\mathrm{O}$ argumento do menor dos males é utilizado para defender qualquer coisa, desde assassinatos-alvos, matanças por misericórdia, demolições de casas, deportações, torturas, até o uso de armas químicas não letais, escudos humanos, e inclusive tornar alguns civis alvos se isso significa salvar mais vidas inocentes do que elas custariam (Weizman, 2011, p. 8-9, livre tradução) 7 .

Enquanto para este autor, no contexto das guerras humanitárias internacionais, há um manejo de cálculo do risco e a construção de medidas e engenharias que legitimam intervenções como a ocupação israelense na Palestina, há aquilo que ele chama como um controlado abandono estatal, no nosso cenário prisional falamos de configurações bem específicas e diferenciadas. Menos pensada em termos de equações humanitárias, onde há um cuidado calculado para a sobrevivência de um mínimo de pessoas e onde os discursos dos direitos humanos se tornam armas (weaponized) para intervenções militarizadas, a política carcerária brasileira transforma a maleabilidade cotidiana em campos de negociações onde a preocupação com os direitos humanos aparece como discurso de soberba intelectual e o Estado é visto como uma entidade metafísica que totalmente abandona o sistema penitenciário. É notável o quanto na segurança pública encontramos a produção, manutenção e reforço da lógica do "abandono estatal”.

\section{Violência do direito, arranjos de legalidades}

Ao nos aproximarmos de uma analítica foucaultiana para discutir o Estado, imediatamente o exercício do pensamento deve voltar-se para a desnaturalização desta noção. Foucault nos convoca a pensar o Estado não como um monstro absoluto, de poder vertical, tampouco reduzido a funções burocráticas, visto através de relações de produção e força. O Estado, sob esta ótica, não é uma individualidade, o Estado é uma prática. Foucault (2008a) nos adverte sobre a existência de certo fascínio e supervalorização exercidos na contemporaneidade sobre as questões voltadas ao Estado: "Sabe-se que fascínio exerce hoje o amor ou o horror ao Estado; sabe-se quanta atenção as pessoas dedicam ao nascimento do Estado, à sua história, à sua progressão, ao seu poder, aos seus abusos" (p. 144). Se adotarmos essa advertência para pensarmos o Estado moderno, evitamos cair em generalizações e/ou reducionismos e passamos a pensá-lo menos como forma, do que um conjunto de forças e ações. Nesse sentido, só é possível visibilizá-lo como uma força no campo da pesquisa ao analisar o presente,

${ }^{6}$ Como parte do Plano Estadual de Segurança Pública do governo de José Ivo Sartori, foram anunciadas 2 mil novas contratações de policiais para agrupar o efetivo da Brigada Militar, somando a isso a retomada dos pagamentos em dia e as horas extras; contudo, tais medidas são apresentadas exatamente quando a aposentadoria de policiais já somavam cerca de 2,8 mil (Gomes, 2017; Rio Grande do Sul, 2016).

${ }^{7}$ No original: "Lesser evil arguments are now used to defend anything from targeted assassinations and mercy killings, house demolitions, deportation, torture, to the use of (sometimes) non-lethal chemical weapons, the use of human shields, and even the intentional targeting of some civilians if it could save more innocent lives than they cost". 
suas formações históricas e "a superposição de inúmeras camadas de vestígios passados" que evocam sua constituição enquanto economia de poder (Coimbra, Knijnik, \& Galli, 2013, p. 46).

Para Foucault (2008a), existem três grandes economias de poder no Ocidente a ver: o Estado de justiça; o Estado administrativo; e o Estado governamental. A primeira diz respeito ao Estado nascido de um território feudal, correspondendo a uma sociedade de lei e litígios; a segunda nasce nos séculos XV e XVI, não mais feudal, mas uma economia relacionada a regulamentações e disciplinas; a terceira economia volta-se para o surgimento da população e da emergência de mecanismos de segurança para defender a sociedade. É importante relatar que tais formas de Estado não surgem uma após a outra, mas se engendram umas nas outras, encadeadamente. Exatamente por compreender que não falamos de uma entidade onipresente e desconexa dos saberes e poderes que o constituem, e constituem mundo, acreditamos que é preciso abordar o problema do Estado a partir das práticas de governo, os efeitos móveis de um regime de governamentalidades, de práticas estatais as quais não estão separadas de ações da sociedade civil, terceiro setor, investimentos públicos ou privados, mas articulam-se e são produzidas na/e a partir das relações na manutenção e gestão das populações. Portanto, procuramos nos interrogar sobre as práticas pelas quais o Estado investe na população: "os procedimentos gerais de internamento e passando assim por trás do asilo, do hospital, das terapias e das classificações, assim como no caso da prisão procuramos passar por trás das penitenciárias propriamente ditas, para tentarmos descobrir a economia de poder" em variadas conjunturas (Foucault, 2008a, p. 161). Mais adiante, em 'Nascimento da Biopolítica', Foucault (2008b) nos traz outra advertência quanto a certos cuidados ao problematizar práticas estatais: não perder as especificidades das análises; não inflacionar para uma "desqualificação pelo pior", demonizando o Estado; e não eliminar a atualidade, a influência que se tem sobre o real, perigo que se acomete ao pensar o Estado como um "fantasma paranoico e devorador" (p. 261).

Em consonância com o pensamento de Foucault, Weizman (2011) analisa as ações de governo a partir de suas táticas moderadas, discorrendo sobre instru- mentos singulares estatais que manejam populações, e como gradualmente certos aparatos jurídicos-legais se tornam instrumentos de governo e extermínio de vidas: "É na sua moderação, ao invés de sua irrestrita aplicação de poder, que a violência do Estado se torna efetiva" (p. 17, livre tradução). Este autor problematiza os debates legais no Estado de direito e seus usos, onde aquilo que ele nomeia por princípio de proporcionalidade - cálculo mínimo da manutenção da vida - se torna o principal tradutor da relação entre violência, lei e seus sentidos políticos. Nesse sentido, os cálculos de proporcionalidade surgem como tecnologias de manejo e governo - o manejo da violência e o governo das populações. "Esse poder se fundamenta na habilidade de calcular, contar, medir, balancear e agir sobre esses cálculos. Inversamente, para se tornar não governável, o sujeito deve se tornar incalculável, incomensurável, inexprimível" (idem). Entre o que é necessário fazer e a mínima proporção dessa conta para que não se chegue até o pior que pode acontecer - o que pode variar desde arcar com algumas mortes até, "em seus momentos mais macabros, ser sugerido os bombardeios atômicos de Hiroshima como algo a ser tolerado sob o argumento de defesa do menor dos males" (p. 9) ${ }^{8}$ - a lógica do "menos mal" ou "poderia ser pior" passa a ser a racionalidade do poder sobre a vida no interior das políticas de segurança. Especificamente no sistema carcerário brasileiro, podemos dizer que o "menor dos males" emerge como uma mecânica burocrática que diz de acontecimentos entre o militar (a militarização da segurança) e arranjos de legalidades.

Principal eixo tematizado por Arendt (1999) em "Eichmann em Jerusalém - um relato sobre a banalidade do mal”, o argumento do menor dos males é indicado para além da metafísica. A autora enseja a dimensão do banal como um mecanismo de normas e valores institucionalizados que transforma a obediência à autoridade na própria lei, uma "obediência cadavérica" (kadavergehorsam), como o próprio Eichmann a nomeou. Em sua cegueira, o banal é perpetrado pela resistência ao pensar, a um certo aprisionamento às funções hierárquicas e maquinaria cotidiana que torna a aceitação consciente do menor dos males um esquecimento do mal em si. Ela deixa claro,

${ }^{8}$ Traduções no original: "Thus it is in its moderation, rather than in its unrestrained applications of power, that state violence becomes effective"; "Moreover this power is grounded in the very ability to calculate, count, measure, balance and act on these calculations. Inversely, to make oneself ungovernable, one must take oneself incalculable, immeasurable, uncountable"; e citação da página 9: "In one of its more macabre moments it was suggested that the atomic bombings of Hiroshima might also be tolerated under the defense of the lesser evil". 
porém, que esse gesto não transcorre como uma escolha, uma vez que o exercício da dúvida e da crítica é sanado, tornando o sujeito consumido pelo vazio do pensamento burocrático. Nesse contexto a violência produz-se na banalidade factual de um cumprimento de ordens que se tornam lei, no dever a um Estado que legitima a morte, e em um poder de matar que se dissemina por todo o corpo social. Podemos trazer os questionamentos de Arendt (1999) ao pensar sobre a complacência dos povos ante sua própria eliminação, e nos perguntarmos como não enxergar a violência do Estado? Ou como é possível enxergá-la e viver? E, sendo o direito um meio para a realização da justiça em sua constituição jurídica, por quais caminhos recusamos formas acríticas de obediência?

Para essa última pergunta Arendt (1999) faz questão de nos lembrar que o direito é a institucionalização da violência: "Nem é preciso acrescentar que a parafernália legal resultante, longe de ser um mero sistema do pedantismo ou empenho alemão, serviu muito eficientemente para dar a toda a coisa a sua aparência de legalidade" (p. 92). Walter Benjamin também o dizia. Para o filósofo a violência do Estado de direito acontece exatamente por meio de sua estrutura jurídica que possibilita tornar a exceção, a regra ${ }^{9}$. Dito de outra forma, a origem da lei cria as condições para as justificativas da violência e seus procedimentos, a fundação do direito faz institucionalizar a violência e, por sua vez, a violência institucionaliza o direito. Benjamin nos diz que a violência na institucionalização do direito tem dupla função: ser o meio para um fim já instituído pelo direito e, por outro lado, instituir do direito o seu próprio aprisionamento, uma vez que o estabelece dependente da violência. O direito, assim, torna-se um fim necessário a partir da violência e vinculado a ela, sob o nome de poder: "A institucionalização do direito é institucionalização do poder e, nesse sentido, um ato de manifestação imediata da violência" (Benjamin, 1986, p. 172).

Nesse ponto tanto Butler (2017) como Agamben (2002), pensadores que discutem sobre a indissociabilidade do fenômeno jurídico e sua relação com a violência, nos lembram da necessidade de retornarmos à crítica benjaminiana sobre essa relação, lançada em seu ensaio "Crítica da Violência - Crítica do Poder" (Benjamin, 1986). Enquanto Agamben (2002) segue o nexo entre vida nua e violência jurídica, sobre os quais ele desenvolverá seus trabalhos sobre a intrínseca relação entre o domínio do direito, a sacralização da vida e estado de exceção, Butler (2017) busca entender como Benjamin (1986) trabalha fontes judaicas para oferecer uma dupla crítica à violência do direito e ao sionismo. Um aspecto que ambos ressaltam é a diferença que Benjamin (1986) traça sobre a violência instauradora do direito (rechtsetzend) e a mantenedora do direito (rechtserhaltend) e, junto a Benjamin (1986), seguem pensando se é possível uma terceira trajetória da violência ${ }^{10}$ que possa ser acionada e produzida contra a coerção do direito, mas que fosse fundamentalmente não violenta, não sanguinária? Para pensarmos sobre esse terceiro limiar, é preciso olhar para as forças de violência articuladas ao direito. Por violência que mantém o direito, Benjamin (1986) refere-se ao modo como somos governados pela força da lei, ou como o direito impõe seus regramentos sobre nossas condutas cotidianas, ao passo que a violência instauradora trata da origem do direito e da justiça, de uma criação vingativa que visa a coerção dos degenerados, dos indisciplinados. Diz Butler (2017) que essa última concepção da violência legal pode ser resumida na afirmação de que "isso vai ser lei", ou, mais enfaticamente, "isso agora é lei". Uma violência declarada por decreto. Se os tribunais e a polícia (não militarizada no caso) exercem a força da violência que mantém o direito, o militar seria a força que cabe nos dois lugares, atuando enquanto poder mantenedor e instaurador. É nesse sentido que Foucault (2002a), ao analisar as formas jurídicas do antigo Direito Germânico, o coloca enquanto um sistema que não opõe guerra à justiça, e onde a possibilidade de interromper uma série de vinganças, caracterizadas como "vingança judiciária”, estaria em consentimentos mútuos, pactos e transações regulamentadas.

Assim, o que aconteceria caso atualizássemos essas forças para o cenário prisional brasileiro? Como pensar uma terceira forma de violência na

\footnotetext{
${ }^{9}$ Tanto Agamben (2002), como Arendt (1999) e Weizman (2011) discutem sobre o estado de exceção em suas obras. Este último, especificamente, discorre sobre como a universalização de direitos humanos internacionais se torna a fundamentação legal para matar um mínimo de pessoas em Gaza, Etiópia, Bósnia, Palestina e Iraque.

${ }^{10}$ Quando à terceira forma de violência que ultrapassem e transcendam as forças instauradoras e mantenedoras que Benjamin traz, ver discussões apresentadas por Agamben (2002) e Butler (2017). Em termos de quadros interpretativos sobre o ensaio de Benjamin, torna-se importante a leitura de "A força da Lei", de Derrida (2010), no qual o autor questiona a crítica benjaminiana e o que ele considera um marxismo messiânico e postura antiparlamentar de Benjamin.
} 
força militar policial? Se atentarmos para o encontro da polícia militarizada com a segurança, a violência do direito encontra-se ao decretar o militar como a figura paradoxal da segurança brasileira: a exceção institucionalizada da força da lei na organização prisional gaúcha. Em nosso sistema, a violência do direito opera ao legitimar a intervenção militar, pensada como solução provisória e intervencionista a princípio, e deslocá-la enquanto reconfiguração política, um modus operandi para o sistema prisional, na manutenção do controle das forças militares sobre instituições prisionais. Em nosso contexto, porém, o sujeito é distinto daquele tomado por um vazio de pensamento, como o burocrata de Hannah Arendt. Ainda que consumido pelo dia, automatizado em funções hierárquicas e mecânicas burocráticas, o militar constitui-se como o defensor e executor da violência do Estado de Direito no âmbito penal. O menor dos males é a esfera de violência que o produz, e em arranjos de legalidades ele encontra sobrevivência. Esses arranjos são encontrados em negociações cotidianas sobre produtos que entram e saem das cadeias gaúchas, moderações de poderes e regramentos articulados entre militares e agentes penitenciários junto a líderes de facções, encontram-se também nos jogos agenciados diariamente entre os diferentes atores prisionais para a sobrevivência e manutenção da própria prisão (desde alugueis pagos por espaços privilegiados nas galerias do PCPA, câmbios escusos realizados sobre produtos ilegais, até o comércio do sexo enquanto forma de controle social ${ }^{11}$ ). Nestes arranjos, o poder não se trancafia em um regime totalitário, mas constitui-se em práticas que consomem as grades de ferro, pluralizando-o: "Meu nome é Legião, poderia ele dizer" (Barthes, 2004, p. 11).

Interessante ressaltar que a semântica para a palavra violência (gewalt) em Benjamin (1986), pode significar ao mesmo tempo poder. Em nota da tradução de seu ensaio para o português, é explicado que há um jogo entre essas palavras que torna ambígua essa relação. Momentaneamente essa situação é resolvida na obra ao colocar um asterisco onde as duas acepções se tornam possíveis: violência*poder. É retomando esse jogo de palavras e símbolos que provocamos as perguntas lançadas anteriormente: "Como não enxergar a violência*poder do Estado?
Ou como é possível enxergá-la e viver?" - nos perguntamos. Respondemos: enxerga-se. vive-se. O que ver e como viver depende de uma série de negociações. Nesse campo de transações e pactos, onde "negociar é a regra e a regra é sempre negociável", a questão passa a ser os arranjos de legalidades que constituem o poder e se tornam os cálculos mínimos na trama de saberes e poderes onde as palavras de ordem voltam-se para mais investimentos com o menos possível. Se pensarmos em suas finalidades estratégicas, a que eles correspondem, para que servem, como funcionam na luta econômica, os tomamos como espaços limiares de negociação da sobrevivência. E nesse aspecto, os arranjos de legalidades desencadeiam o que poderíamos arriscar a tomar como uma terceira forma de violência marcada por provocar um paradoxo no sistema legal ao não desfazer os fundamentos do direito (não há rupturas ou contravenções legais), mas a invocação a uma determinada ética vinculada a um imperativo "que não impõe, mas deixa em aberto os modos de sua aplicabilidade e suas possibilidades de interpretação, incluindo as condições em que pode ser recusado" (Butler, 2017, p. 80).

Ao pensarmos em arranjos de legalidades, os diferenciamos daquilo que Carvalho (2013) nomeia como dobras de legalidade. Estas últimas dizem de um excesso normativo na política criminal de drogas, mais especificamente zonas contraditórias e dúbias quanto à compreensão e à execução da Lei No $11.343 / 2006$, especialmente no que tange ações incriminadoras das agências penais. Enquanto por arranjos de legalidades pensamos em como são produzidos e legitimados campos de negociação, que não necessariamente se preocupam em justiça ou o alcance de um bem maior. Estes são encontrados nas ações retributivas em troca de favores e na manutenção de um status operandi prisional, uma racionalidade que está menos para uma ordem messiânica que visa um fim maior, do que para a institucionalização da sobrevivência. Isto não significa dizer que a violência não componha e seja produzida por estes espaços, ou ainda que vidas não sejam matematicamente calculadas para morrer; pelo contrário, há a instauração de barbáries, mas elas se transformam em sutis e morféticos meios, que não encontram fins.

\footnotetext{
${ }^{11}$ Para a discussão sobre a visita íntima e o sexo como dispositivo de poder na esfera prisional, ver Bassani (2015).
} 


\section{Considerações finais: cálculos estatais e o jogo morfético do encarceramento}

Os cálculos estatais relacionados ao sistema prisional brasileiro têm se constituído tanto pelos investimentos financeiros no encarceramento, corpos físicos de policiais e mais aprisionamentos, quanto na busca pelas causas, responsáveis e culpados pela situação atual de índices de criminalidade e aumento no número de pessoas presas. Questionar como organizam-se as relações pautadas na lógica de segurança é provocar estranhamento em relação a um estado naturalizado de violências, estremecer, também, os cálculos articulados sobre vidas, além de possibilitar desconforto frente a banalizações de morte, como quando questiona-se o papel do Estado frente às rebeliões que se alastraram nos últimos tempos ${ }^{12}$.

Diante do exposto, é possível compreender que os investimentos realizados não têm produzido redução no cometimento de crimes ou a melhora nas condições carcerárias, mas, sim, a ampliação das formas de encarceramento que incidem sobre corpos constituídos enquanto criminosos. Operacionalizam-se, assim, medidas que se pautam em um arranjo arbitrário de legalidades que permite que qualquer ação seja realizada em nome da segurança, tais medidas podem ser visualizadas na contenção de corpos em ônibus-cela, contêineres, aprisionamento dentro de viaturas e, até mesmo, algemamento das pessoas detidas em lixeiras. Trata-se, portanto, de um cálculo mínimo sobre vidas a serem gerenciadas em um plano de investimento entre baixos custos e a menor repercussão possível, combinada com a ampliação e execução de práticas violentas.

Nesse cenário, encontramos diversos atores que ocupam o lugar daqueles que matam e, concomitantemente, dos que morrem nesse jogo de cálculos sobre vidas e grades. Pode-se dizer que é estabelecido um jogo onde a provisoriedade se torna eternidade para o efetivo da Brigada que continua na coordenação do Central, para os capitães e soldados e tenentes que levam pessoas ao fundo das galerias, para os presos provisórios que continuam sem a determinação de suas sentenças, para os grupos que visitam a prisão em buscas de provas óbvias de violências, para os escritores de relatórios que narram denúncias sem fins, para produtores de séries e documentários sobre prisões, enfim... -; um jogo onde uma série de atores arbitram danos e responsabilidades, definem julgamentos e direitos, regulamentam transações e mecanismos penais; um jogo em que os arranjos de legalidades produzem um deslocamento da violência do direito para soluções da ordem do ubuesco. A perversão não toma conta dos arranjos, pois não há necessariamente o desejo de morte, mas tampouco se preocupa em como se vive. As soluções pautadas, assim, respiram um ar dos limiares entre o que não pode jamais acontecer novamente (como uma grande rebelião, sequestros e um número muito grande de mortes) e o ideal a que nunca chegaremos (estabelecimentos prisionais vazios).

Esse jogo morfético se mantém e é produzido junto a campos de saber e narrativas especialistas, que mantêm e instauram a violência do direito. Em entrevista realizada para o Sindicato dos Professores de Porto Alegre, o juiz que coordena as Audiências de Custódia no Central é questionado sobre políticas de curto e médio prazo que poderiam ser implantadas como possibilidades para a redução da violência e o papel da educação frente a isto:

No curto prazo, pouca coisa. Mas, no médio prazo, bastante. Medidas que independem de qualquer política nacional ou de mudança de lei federal. [...] Por exemplo: o Rio Grande do Sul hoje tem uma das menores taxas de fecundidade do Brasil. Mas não entre as classes baixas. Por quê? Porque falta conhecimento, educação etc., para que aquela menina não tenha filhos naquele momento. Hoje, qualquer menina de classe média, ou nem tão média, terá filhos após os 25 anos. Às vezes, depois dos 30 . Primeiro ela vai se formar, conseguir um emprego, e depois será mãe. É um padrão que vem se consolidando, mas que na classe pobre não se repete. Nela as meninas continuam tendo filhos com 15 anos, com $16,17,18,19$. Fazer com que essa menina tenha filhos após os 25 anos é uma política pública. E

\footnotetext{
${ }^{12}$ Em 2016 rebeliões foram registradas por todo o país. No decorrer do ano testemunhamos rebeliões sanguinárias como a do Complexo Penitenciário Anísio Jobim (Compaj) em Manaus, repercutindo como o maior massacre do sistema prisional do Amazonas, onde ocorreram decapitações de presos; rebeliões em São Paulo e Rio de Janeiro que se alastraram para o restante do país sendo consideradas um sinal de rupturas e confrontos entre as duas maiores facções do país, o Comando Vermelho (CV) e o Primeiro Comando da Capital (PCC); bem como rebeliões nos presídios do Rio Grande do Sul em função da greve da Susepe motivada pelo pacote de medidas e cortes do governo Sartori.
} 
não é difícil. Basta ela poder colocar um implante quando começar a menstruar, e mantê-lo até os 25 anos, com as devidas substituições (Brzuska, 2016, p. 6).

A repórter questiona se tal iniciativa não seria polêmica, uma problemática que envolveria os direitos da pessoa e procedimentos éticos referentes à escolha da adolescente e dos pais. A resposta é enfática: "Não há problemas. Estamos assegurando para ela os mesmos direitos das meninas de classe alta". Pela ordem do direito ao direito, é possível obrigar alguém sem que seja punição. É possível forçá-la como sendo direito. Da mesma forma desloca-se quaisquer moralismos que possam estar atrelados ao mandato, pois "estamos assegurando a ela os mesmos direitos", conservando a pessoa onde ela deveria estar, aprisiona-se o desejo, seus comportamentos e virtualidades. Sem mencionar que toda a questão se resume à classe pobre, reduzindo a violência à falta de formação, de emprego e de uma família bem planejada. A correção do sujeito periculoso só não atinge as formas arcaicas medievais, pois não se desmembram em súplicas públicas os sujeitos, mas se adotam medidas totalitárias na materialização de ordens que independem de leis. Ele continua: "Elas não estão sendo castradas. Só recebendo um contraceptivo de efeito demorado que será substituído algumas vezes até que ela complete 25 anos. É uma política pública que não precisa de lei" (Brzuska, 2016, p. 6). Afinal, pior seriam presídios superlotados. "Menos mal, então".

E nenhuma barbaridade ocorre na sociedade sem que cultivem, os cientistas de plantão e muitos togados, argumentos para justificar a sua legitimidade, a sua legalidade e a sua necessidade, e explicar que não havia hipótese de ser diferente, mantendo-se, outrossim, a estrutura social através do medo, ali pressentido e instaurado desde sempre, querendo abafar o último suspiro de uma crítica moribunda (Pandolfo, 2014, p. 214).

Portanto, menos do que uma figura vestida em verde, cinza e bege, o militar se torna o personagem que ultrapassa um sujeito da força da lei gerenciando corredores prisionais no Rio Grande do Sul, mas se torna a alegoria que passa a dizer de um campo de negociações em aberto. Exatamente por seu caráter paradoxal, e pela força de violência fundadora e preservadora do direito, essa figura produz tanto o medo quanto a vida ao conduzir negociações e transações barbaramente legais. Por também ser encontrado em outras instâncias da segurança esse personagem é o mais difícil de nomear. O militar e os arranjos de legalidades também se encontram na palavra máxima da lei - na presença do juiz e em suas pretensões de não mexerem em estruturas legais para coagir sujeitos, na figura do especialista que discorre sobre soluções e destinos do cárcere, nos olhares curiosos e sedentos que tratam de gravar séries entre grades, nos decretos que pedem mais vagas, nos planos de investimentos e reutilizações de projetos e engenharias para novos pavilhões e, por esta razão, o militar diz de uma força de exceção e cálculos morféticos na esfera prisional. Contudo, ao considerarmos as atuais conjunturas do sistema penitenciário brasileiro e, no momento em que este artigo problematiza as relações de uma cadeia pública militarizada, seu espectro nessa brecha narrativa se configura por essa forma-força. Calçando coturnos e colocando em jogo não um status representativo, mas uma relação política com a prisão e sua falibilidade, uma experiência do cárcere.

\section{Referências}

Agamben, G. (2002). Homo Sacer. O poder soberano e a vida nua I. (H. Burigo, Trad.). Belo Horizonte, MG: Editora UFMG.

Arendt, H. (1999). Eichmann em Jerusalém: Um relato sobre a banalidade do mal. São Paulo, SP: Companhia das Letras.

Barthes, R. (2004). Aula. São Paulo, SP: Cultrix.

Bassani, F. (2015). Visita íntima: Sexo, crime e negócios nas prisões. Porto Alegre, RS: Bestiário.

Benjamin, W. (1986). Documentos de cultura, documentos de barbárie (Escritos escolhidos, C. Sousa et al., Trads.). São Paulo, SP: Cultrix. 
Benjamin, W. (1987). Magia e técnica, arte e política (3a ed., Obras escolhidas, Vol.1, S. P. Rouanet, Trad.). São Paulo, SP: Brasiliense.

Brasil. Ministério da Justiça, Secretaria Nacional de Segurança Pública (SENASP). (2003). Rede Nacional de Altos Estudos em Segurança Pública (Renaesp): Repositório institucional. Brasília, DF: o autor. Recuperado de http:// repositorio.enap.gov.br/handle/1/260

Brzuska, S. (2016, setembro 9). Presídio central: Punições e resistências. Seminário de Extensão: Abolindo prisões de dentro pra fora: Experimentações da Inglaterra e do Brasil. Porto Alegre, RS: UFRGS.

Butler, J. (2017). Caminhos divergentes: Judaicidade e crítica do sionismo. São Paulo, SP: Boitempo.

Canofre, F. (2017, fevereiro 11). Por que o Presídio Central e outras cinco unidades prisionais mudaram de nome no RS?. Sul21. Recuperado de http://www.sul21.com.br/jornal/por-que-o-presidio-central-e-outras-cinco-unidades-prisionais-mudaram-de-nome-no-rs/

Carvalho, S. (2006). Política de guerra às drogas na América Latina entre o direito penal do inimigo e o estado de exceção permanente. Crítica Jurídica, 1(25),.253-267.

Carvalho, S. (2013). Nas trincheiras de uma política criminal com derramamento de sangue: depoimentos sobre os danos diretos e colaterais provocado pela guerra às drogas. In: A. Ximendes, C. Reis, \& R. Wolski. Entre garantia de direitos e práticas libertárias (pp.67-86). Porto Alegre, RS: CRPRS.

Coimbra, C.; Knijnik, L.; Galli, T. M. (2013). Qual a cor da farda dos guardiões da ordem? Algumas problematizações sobre a história do Brasil contemporâneo. In: A. Ximendes; C. Reis; R. Oliveira (Orgs.). Entre garantia de direitos e práticas libertárias. pp.43-49. Conselho Regional de Psicologia, Porto Alegre.

Correio do Povo. (2016, 30 nov). Ônibus-cela recebe primeiro preso em Porto Alegre. Recuperado de http://correiodopovo.com.br/Noticias/Policia/2016/11/604269/Onibuscela-recebe-primeiro-preso-em-Porto-Alegre

Costa, I. F. (2011). A Rede Nacional de Altos estudos em Segurança Pública. \#Carta. Sociedade. Recuperado de http://www.cartacapital.com.br/sociedade/a-rede-nacional-de-altos-estudos-em-seguranca-publica

Decreto No 46.225, de 17 de fevereiro de 2009. Abre créditos suplementares no Orçamento do Estado. Diário Oficial do Rio Grande do Sul, 7 fev. 2009

Decreto No 53.176, de 25 de agosto de 2016. Abre créditos no Orçamento do Estado. Diário Oficial do Rio Grande do Sul, 11 nov. 2016b.

Decreto No 53.297, de 10 de novembro de 2016. Cria, extingue e altera a denominação de estabelecimentos prisionais no âmbito do Estado do Rio Grande do Sul. Diário Oficial do Rio Grande do Sul, 11 nov. 2016 a.

Derrida, J. (2010). Força de lei: O fundamento místico da autoridade (2a ed.). São Paulo, SP: Martins Fontes.

Dornelles, R. (2017, fevereiro 3). Facções avançam e dominam o Presídio Central de Porto Alegre. Zero Hora, Segurança Já. Recuperado de http://zh.clicrbs.com.br/rs/noticias/policia/noticia/2017/02/faccoes-avancam-e-dominam-o-presidio-central-de-porto-alegre-9713182.html

Earle, R. (2011). Prison and university: A tale of two institutions? British Society of Criminology, 4(6), 20-37.

Foucault, M. (2005). Em defesa da sociedade: Curso no Collège de France (1975-1976) (4a ed.). São Paulo, SP: Martins Fontes.

Foucault, M. (2006). A prisão em toda parte (1971). In M. Foucault, Ditos e escritos IV: Estratégia, poder, saber (2a ed., pp. 26-27). Rio de Janeiro, RJ: Forense Universitária.

Foucault, M. (2008a). Segurança, território, população: curso no Collège de France (1977-1978). São Paulo, SP: Martins Fontes.

Foucault, M. (2008b). Nascimento da biopolítica. São Paulo, SP: Martins Fontes.

Foucault, M. (2013). Os anormais: Curso no Collège de France (1974-1975). São Paulo, SP: Martins Fontes.

Gagnebin, J. M. (2008). Documentos da cultura/Documentos da barbárie. IDE, 31(46), 80-82.

Gomes, L. E. (2017, fevereiro 24). Para reduzir violência, RS precisa prender melhor, não mais, e investir nos servidores, dizem especialistas. Sul 21, 24 de fevereiro. Porto Alegre. Recuperado de http://www.sul21.com.br/jornal/ para-reduzir-violencia-rs-precisa-prender-melhor-nao-mais-e-investir-nos-servidores-dizem-especialistas/. 
Jacobsen, G. (2016, setembro 11). Detentos se rebelam. Correio do Povo, Polícia. Recuperado de http://www.correiodopovo.com.br/Noticias/Pol\%C3\%ADcia/2016/9/597455/Detentos-se-rebelam-e-colocam-fogo-em-cela-de-delegacia-de-Porto-Alegre

Kannenberg, V. (2016, outrubro 26). Cena repetitiva. Zero Hora. Polícia. Recuperado de http://zh.clicrbs.com.br/ rs/noticias/policia/noticia/2016/10/com-celas-de-delegacias-lotadas-presos-voltam-a-ficar-em-viaturas-em-porto-alegre-8020178.html

Ledur, P. (2016, novembro 16). Polícia improvisa micro-ônibus para abrigar presos em Porto Alegre. G1 Globo, RBSTV. Recuperado de http://gl.globo.com/rs/rio-grande-do-sul/noticia/2016/11/policia-improvisa-micro-onibus-para-abrigar-presos-em-porto-alegre.html

Lei No 7.209, de 11 de julho de 1984. Altera dispositivos do Decreto-Lei no 2.848, de 7 de dezembro de 1940 - Código Penal, e dá outras providências. Diário Oficial da União, 13 jul. 1984.

Lei No 9.714, de 25 de novembro de 1998. Altera dispositivos do Decreto-Lei no 2.848, de 7 de dezembro de 1940 Código Penal. Diário Oficial da União, 26 nov. 1998.

Lei No 11.343, de 23 de agosto de 2006. Institui o Sistema Nacional de Políticas Públicas sobre Drogas - Sisnad; prescreve medidas para prevenção do uso indevido, atenção e reinserção social de usuários e dependentes de drogas; estabelece normas para repressão à produção não autorizada e ao tráfico ilícito de drogas; define crimes e dá outras providências. Diário Oficial da União, 24 ago. 2006.

Leibniz, G. W. Ensaios sobre a Teodiceia: Sobre a bondade de Deus, a liberdade do homem e a origem do mal. Rio de Janeiro, RJ: Estação Liberdade, 2017.

Lima, R. K. (2004). Os cruéis modelos jurídicos de controle social. Revista Insight Inteligência, 6(25), 130-47.

Lima, R. S., Bueno, S., \& Mingardi, G. (2016). Estado, políticas e segurança pública no Brasil. Revista Direito GV, 12(1), 49-85. https://doi.org/10.1590/2317-6172201603

Márquez, G. G. (2014). Cem anos de solidão (83a ed., E. Nepomuceno, Trad.). Rio de Janeiro, RJ: Record.

Martins, C., Abati, L., \& Rosa, V. (2015, novembro 30). Presídio Central de Porto Alegre é interditado pela quarta vez no ano. ClicRBS, Caso de Polícia. Recuperado de http://wp.clicrbs.com.br/casodepolicia/2015/11/30/presidio-central-de-porto-alegre-e-interditado-pela-quarta-vez-no-ano/?topo=52,1,1,,171,e171

Massumi, B. (2016). O capital (se) move (Caixa Pandemia de Cordéis). São Paulo, SP: n-1 edições.

Moreira, C. I. (2015, março 11). "Eu não teria demolido o pavilhão C", afirma novo diretor do Central. Zero Hora. Troca de Comando. Recuperado de http://zh.clicrbs.com.br/rs/noticias/noticia/2015/03/eu-nao-teria-demolido-o-pavilhao-c-afirma-novo-diretor-do-central-4716560.html

Nunes, A. (2016, setembro 28). Em busca do futuro perdido. Veja, 49(39), 54-59.

Pandolfo, A. C. (2014). Um sopro de crítica à violência e ao crime. Sistema Penal \& Violência, 6(3), 211-214.

Requião, F. (2016, outrubro 15). "Central” brilha no Festival do Rio e vai virar série na tevê a cabo. Diário Gaúcho. Entretenimento. Recuperado de http://diariogaucho.clicrbs.com.br/rs/entretenimento/noticia/2016/10/central-brilha-no-festival-do-rio-e-vai-virar-serie-na-teve-a-cabo-7788472.html

Rio Grande do Sul. Secretaria de Segurança Públic,a. (2016). Plano Estadual de Segurança Pública: Material de apoio. Porto Alegre, RS: o autor.

Ruas, C. (2016, janeiro 21). Bem-vindo ao inferno do Presídio Central. Risca Faca. Recuperado de http://riscafaca. com.br/comportamento/a-chave-do-casarao/

Sager, T., Rodrigues, B. (Produtores), Sager, T., \& Dornelles, R. (Direção e Roteiro). (2015). Central. Porto Alegre, RS: Panda Filmes.

Souza, G. A. D. (2014). "Punir menos, punir melhor”: Discursos sobre crime e punição na produção de alternativas à prisão no Brasil (dissertação de mestrado). Programa de Pós-Graduação em Ciências Criminais, Faculdade de Direito, Pontifícia Universidade Católica do Rio Grande do Sul, Porto Alegre, RS, Brasil.

Sturn, H. A. (2013, novembro 4). Reformas lançam dúvidas sobre demolição do Presídio Central em Porto Alegre. Zero Hora. Recuperado de http://zh.clicrbs.com.br/rs/noticia/2013/11/reformas-lancam-duvidas-sobre-demolicao-do-presidio-central-em-porto-alegre-4322065.html 
Torres, E. (2016, outubro 21). Caos prisional. Zero Hora. Polícia. Recuperado de http://zh.clicrbs.com.br/rs/noticias/policia/noticia/2016/10/com-celas-lotadas-delegacias-de-porto-alegre-tem-novos-presos-em-viaturas-7871895.html

Weizman, E. (2011). The least of all possible evils: Humanitarian violence from Arendt to Gaza. London: Verso.

\section{Oriana Hadler}

Professora Adjunta no Departamento de Psicologia Social e Institucional da Universidade Federal do Rio Grande do Sul (UFRGS), Porto Alegre - RS. Brasil.

E-mail: orianahadler@gmail.com

(iD) https://orcid.org/0000-0001-9736-2224

Neuza Maria de Fátima Guareschi

Professora Associada da Universidade Federal do Rio Grande do Sul (UFRGS), Porto Alegre - RS. Brasil.

E-mail: nmguares@gmail.com

(iD) https://orcid.org/0000-0001-5892-188X

Endereço para envio de correspondência:

Rua General Souza Doca 270/301

CEP 90630050

Porto Alegre Rs

Recebido 28/08/2018

Aprovado 04/09/2018

Recebido 08/28/2018

Aprovado 09/04/2018

Recebido 28/08/2018

Aprovado 04/09/2018

Como citar: Hadler, O., \& Guareschi, N. M. F. (2018). Investimentos no cárcere: Investimentos no Cárcere: O menor dos males na política de segurança pública. Psicologia: Ciência e Profissão, 38(n.spe.2), 10-26. https://doi.org/10.1590/1982-3703000213634

How to cite: Hadler, O., \& Guareschi, N. M. F. (2018). Investments in the Jail: The lesser of two evils in public security policy. Psicologia: Ciência e Profissão, 38(n.spe.2), 10-26. https://doi.org/10.1590/1982-3703000213634

Cómo citar: Hadler, O., \& Guareschi, N. M. F. (2018). Inversiones en la Cárcel: El menor de los males en la política de seguridad pública. Psicologia: Ciência e Profissão, 38(n.spe.2), 10-26. https://doi.org/10.1590/1982-3703000213634 